\title{
Constituição de identidades étnico-linguísticas e práticas de letramentos em comunidades bilíngues/multilíngues de descendentes de poloneses no Paraná
}

\author{
Bemardete Ryba \\ Universidade Federal do Paraná (UFPR), Curitiba, Paraná, Brasil \\ bernardeteryba@gmail.com
}

\section{DOI: $\underline{\text { http://dx.doi.org/10.21165/el. v45i2.673 }}$}

\begin{abstract}
Resumo
A pesquisa, apresentada neste artigo (e que se encontra em fase inicial), possui como objetivo abordar a constituição étnico-linguística e as práticas de letramentos em comunidades bilíngues/multilíngues de descendentes de poloneses situadas no Estado do Paraná, mais especificamente nos municípios de São Mateus do Sul e Cruz Machado. Como "pano de fundo", apresentamos a fundação das primeiras escolas polonesas no Brasil - Paraná, por entender que o espaço escolar é um dos principais instrumentos para se atingir o propósito do conhecimento da cultura e do uso da língua e, portanto, fundamental para os imigrantes, principalmente para os mais jovens, que aportam outros países. Nesse enfoque, a escola propicia transitar em sociedades onde há identidades culturais múltiplas.
\end{abstract}

Palavras-chave: identidades étnico-linguísticas; práticas de letramentos; descendentes de poloneses.

Establishment of ethno-linguistic identities and literacy practices in bilingual/multilingual communities of Polish descendants in Paraná

\begin{abstract}
The research presented in this paper (which is in its initial phase), has the purpose of approaching the ethnic and linguistic constitution and literacy practices in bilingual/multilingual communities of Polish descendants located in the State of Paraná, more specifically in the municipalities of São Mateus do Sul and Cruz Machado. As a "background", we present the foundation of the first Polish schools in Brazil - Paraná, considering that the school is one of the main instruments to achieve the purpose of culture know ledge and the use of language and, therefore, being essential for immigrants, especially for the younger ones arriving in other countries. In this approach, the school provides people with mobility in societies where there are multiple cultural identities.
\end{abstract}

Keywords: ethnic and linguistic identities; literacy practices; Polish descendants.

\section{Introdução}

Tomamos como base, neste artigo, para discutir a constituição de identidades, as ideias de Bhabha (2003) de que o ser humano se encontra em constantes atos de se reconstruir e se reinventar e que esses atos ocasionam (re)construções de suas culturas e de identidades; de Hall (2003, p.38) de que as identidades são "sempre incompletas", estão sempre "em processo", sempre "sendo formadas" e de Coracini (2003, p.13) de que a crise de identidade que muitos estudiosos acreditam estarmos vivendo é provocada pela "ideologia da globalização que pretende a homogeneização de tudo e de todos" e que "como que por efeito de resistência, as línguas minoritárias ou os dialetos 
em vias de desaparecimento, os grupos marginalizados se rebelam, acirrando as diferenças, lutando por sua sobrevivência e por um espaço na sociedade".

A unicidade da língua em um território nacional, ideal ainda perseguido por alguns, segundo Rodrigues (2002, p.11), é um mito, pois não há língua que seja, em toda a sua amplitude, um sistema uno, invariado, rígido:

Ainda que freqüentemente se defina cada língua como um sistema de comunicação [...]. $\mathrm{Na}$ realidade, toda língua, quer sirva a uma grande nação consideravelmente extensa e muito diferenciada cultural e socialmente, quer pertença a uma pequena comunidade isolada de apenas poucas dezenas de indivíduos é um complexo de variedades, um conglomerado de variantes.

Além da língua portuguesa, considerada a língua oficial, há no Brasil, classificado pela UNESCO como um país multilíngue, de acordo com Bagno e Rangel (2005), cerca de 200 línguas diferentes - aproximadamente 170 indígenas e as demais trazidas por imigrantes. Essas línguas minoritárias - usamos aqui a definição de Dubois (2007) "toda e qualquer língua falada por uma minoria num estado nacional" - muitas vezes são "apagadas", pois seus falantes e descendentes percebem que elas não são valorizadas/prestigiadas no meio social escolhido para viver. Uma dessas línguas minoritárias é a língua polonesa presente em algumas comunidades do Paraná.

\section{A vinda para o Brasil, a religiosidade e a construção das primeiras escolas polonesas - para entender a constituição das identidades dos descendentes de poloneses}

$\mathrm{O}$ fator preponderante que ocasionou a vinda de imigrantes poloneses para $\mathrm{o}$ Brasil foi a desagregação do país, ocasionada pelas invasões de três potências em fins do século XVIII: Prússia, Áustria e Rússia e, mais tarde, Alemanha. O esfacelamento do país trouxe também a desagregação da economia agrária, provocando a saída da terra natal. Em Wachowicz (1981, p.11), temos:

Foi este camponês, que viveu o regime senhorial no limitado mundo de sua aldeia ou de sua região, ou o filho do mesmo, que emigrou para o Brasil, não suportando as campanhas sistemáticas que os governos estrangeiros realizavam para tirar-lhe a propriedade da terra, as perseguições contra sua própria língua e cultura e o sistema agrário caótico. Esses fatores facilitaram a emigração orientada para o Brasil.

Foi pela situação vivida (medo da perda das terras e perseguição pelo uso da língua e cultura) que o patriotismo polonês/espírito nacionalista, denominado "polonidade" (segundo Wachowicz, 1981, p.11), adquiriu características de desconfiança, introspecção, submissão e ressentimento, sentimentos que foram trazidos para as terras brasileiras que os receberam nas imigrações. A Polônia dominada (impérios russo, prussiano, austríaco e, mais tarde, alemão) não possuía um estado capaz de promover o nacionalismo, ou seja, um sentimento nacional em sua forma tradicional. Segundo Hobsbawm (1990), esse nacionalismo ocorreu de forma particular e com características diferentes em contextos variáveis e foi feito sob a liderança de intelectuais poloneses com o objetivo de recuperar a independência do país. Ainda, segundo Hobsbawm (1990), o nacionalismo polonês voltou-se à recuperação do estado (Polônia), fundamentado mais na religião (catolicismo) que na "unidade lingüística"; havia muitos dialetos e línguas e o catolicismo polonês foi significativo para "manter viva" a consciência nacional polonesa. 
A vinda desses imigrantes ao Brasil tinha o intuito de suprir a falta de mão de obra agrária, principalmente nas fazendas de café do país, ocasionada pela abolição da escravidão africana em 1888 - segundo Wachowicz (1970a), cerca de 45\% localizaramse no Rio Grande do Sul, 40\% no Paraná e 15\% em Santa Catarina, São Paulo, Espírito Santo e Minas Gerais.

Após chegarem ao Brasil e dirigirem-se às terras a eles destinadas, grande parte dos imigrantes estabeleceu-se em Santa Catarina, mas, logo a seguir, muitos vieram para o Paraná. Oliveira (2010, p.83) nos informa que "esse grande número prenunciava não apenas o impacto futuro que a comunidade exerceria sobre a sociedade local, mas também as novas formas de organização social e cultural que esta pouco a pouco adotaria".

No Paraná, as maiores "colônias polonesas" (termo muito usado pelos próprios descendentes dessa etnia) são Curitiba, São Mateus do Sul, Mallet e Cruz Machado (WACHOWICZ, 1981). Uma vez fixados em suas colônias, iniciavam a construção de suas casas e de "estradas" (rudimentares) que thes propiciassem alguma comunicação e faziam as primeiras plantações, a fim de assegurar a sua subsistência. A próxima etapa era a construção de uma capela ou igreja católica. Depois, segundo Wachowicz (1970b, p.19), "reuniam-se novamente os colonos, agora para resolverem o problema da alfabetização de seus filhos". O mesmo historiador nos informa que o índice de analfabetismo na parte do território polonês sob o domínio prussiano era 3\%; na região sob o jugo austríaco, $41 \%$ e $60 \%$ onde havia o domínio russo. Além disso, no Paraná, contar com a ajuda do governo esbarrava na falta de recursos materiais e humanos e "esse fato contribuiu para o retardamento da aculturação dessas populações na comunidade brasileira" (WACHOWICZ, 1970b, p.19), pois:

Era bem real a impossibilidade de se darem professores nacionais às crianças polonesas, ou de qualquer outra nacionalidade, devido ao fato do desconhecimento da língua portuguesa pelas mesmas. Como poderia o Govêrno, que ainda lutava com a falta absoluta de professores competentes para as próprias crianças brasileiras, proporcionar professores para os estrangeiros?

(WACHOWICZ, 1970b, p.20).

Os imigrantes, diante desse fato, construíram as escolas para os seus filhos, via de regra, junto às capelas ou igrejas e procuraram trazer um padre polonês para ministrar as aulas. Lembramos aqui Woodward (2009, p.27), ao citar Hall (1990) e dizer que para afirmar determinada identidade "podemos legitimá-la por referência a um suposto e autêntico passado" e "o sujeito fala, sempre, a partir de uma posição histórica e cultural específica" - na busca por um padre polonês católico, os imigrantes contariam com as práticas de letramentos em língua polonesa, bem como com as práticas religiosas (e, o consequente, letramento litúrgico) de sua terra natal. A comunidade que não conseguia esse intento, contava, quase sempre, com a boa vontade das pessoas que faziam parte da comunidade (os colonos poloneses) que se dispunham a ensinar às crianças o que sabiam.

Como, em muitos aspectos, a vida dos imigrantes poloneses e seus descendentes que vieram para o Brasil é marcada pela fé católica e esse fato é um traço identitário que está intimamente ligado às práticas de letramentos escolares - escolas construídas junto às igrejas, padres sendo professores - apontamos, a seguir, algumas práticas religiosas que pudemos observar no município de Cruz Machado: 
- Vigilia de Natal - celebração/missa com a partilha de "oplatek", pão ázimo feito de uma massa finíssima - mesmo processo como são feitas as hóstias da comunhão do catolicismo - conhecido como "pão dos anjos".

- Bênção dos alimentos no sábado anterior à Páscoa - as familias levam os ingredientes que serão usados na elaboração dos pratos a serem servidos no Domingo de Páscoa para que o sacerdote asperja água benta sobre eles.

- Confecção de "pisanki” - arte popular polonesa, tradicional na região da Cracóvia (de onde vieram muitos imigrantes). Os ovos de galinha são perfurados para a retirada da clara e da gema. São feitos desenhos simbólicos (com cera de abelha) e são coladas palhas dos grãos de trigo (que representam o pão alimento abençoado por Deus) coloridas.

- Terços - prática de reza diária, comum principalmente na zona rural e, via de regra, em língua polonesa, realizada por volta das 18 horas. Em algumas casas, há um altar com imagens de santos, principalmente Nossa Senhora de Czestochowa (no Brasil, Nossa Senhora do Monte Claro).

- Missas de domingos e dias santos - rezadas em língua polonesa.

- Catecismos - ensinamentos religiosos direcionados às crianças - diversas preces e cânticos são ensinados em língua polonesa. Há a prática de letramentos litúrgicos em língua polonesa e portuguesa.

Essas práticas religiosas constituíram e constituem as identidades dos descendentes dos poloneses no Paraná e, de acordo com Durkheim (1954), citado em Woodward (2009, p.41) "a religião é algo eminentemente social. As representações religiosas são representações coletivas; os ritos são uma maneira de agir que ocorre quando os grupos se reúnem, sendo destinados a estimular, manter ou recusar certos estados mentais nesses grupos" e, ainda "sem símbolos, os sentimentos sociais teriam uma existência apenas precária". Tendo em vista que em algumas práticas religiosas dos descendentes de poloneses há a presença de letramentos litúrgicos, lembramos Street (2014, p.205) que nos orienta que "estudos confirmam que a maior parte da aprendizagem ocorre fora dos estabelecimentos de educação formal. A maior parte da aprendizagem humana não ocorre em contextos formais". No contexto religioso, há práticas de letramentos em língua portuguesa e polonesa.

Além das práticas de letramentos litúrgicos, verificamos que na localidade de Santana, situada no interior do município de Cruz Machado, em 2014, aconteceram aulas de língua polonesa no CELEM. A seguir, traremos à discussão algumas ideias e teóricos que nos embasam na questão letramentos.

\section{Práticas de letramentos - mais um pouco de identidades}

Embora, durante décadas, tenhamos usado somente a palavra "alfabetização" e a discussão em torno do aprendizado tenha se circunscrito em torno da premissa de que a apropriação da leitura e da escrita era constituída apenas de aspectos mecânicos e funcionais, restringida às habilidades de codificação e decodificação dos símbolos gráficos, hoje, consideramos que alfabetização e letramento são dois processos diferentes, mas indissociáveis, segundo Soares (2002). Esses dois processos envolvem processos cognitivos e metodológicos diferentes para cada pessoa e, de acordo com os estudos de Ferreiro e Teberosky (1985), as pessoas percorrem longos e diferentes caminhos para compreender as características, o valor e a função da escrita. 
Apenas com a aquisição da tecnologia da escrita - a alfabetização - não se tem entrada no mundo da escrita. É necessário o desenvolvimento de competências para o uso da leitura e da escrita nas práticas sociais que as envolvem, ou seja, não basta apropriar-se da tecnologia - saber ler e escrever apenas como um processo de codificação e decodificação, mas é necessário apropriar-se das habilidades que possibilitem ler e escrever de forma adequada e eficiente nas diversas situações em que precisamos ou queremos ler e escrever diferentes gêneros e tipos de textos, em diferentes suportes, para diferentes objetivos, em interações com diferentes interlocutores e para diferentes funções.

Por oportuno, lembramos que após mais de um século da época que marcou o início da criação de leis que estabeleceram o ensino obrigatório nas escolas públicas e gratuitas (1880), a difusão das ideias de Ferreiro e Teberosky (1985) fizeram crescer o interesse pelos temas alfabetização/letramentos, não só entre os pesquisadores, mas também entre grande número de professores. Segundo as autoras, o fracasso nas séries iniciais atinge de modo perverso os setores marginalizados da população. Também apontam para o fato de que a aprendizagem não é tarefa exclusiva da escola; em Ferreiro e Teberosky (1985, p.11), temos:

Pretendemos demonstrar que a aprendizagem da leitura, entendida como questionamento a respeito da natureza, função e valor desse objeto cultural que é a escrita, inicia-se muito antes do que a escola imagina, transcorrendo por insuspeitados caminhos. Além dos métodos, dos manuais, dos recursos didáticos, existe um sujeito que busca a aquisição de conhecimento, que se propõe problemas e trata de solucionálos, seguindo sua própria metodologia.

Com relação às práticas de letramentos nas comunidades de imigrantes e seus descendentes, lembramos Jung (2002, p.1187), que nos diz: "As práticas de letramento são o local em que alguns conflitos emergem, uma vez que o letramento em português representa a cultura dominante e, nesse sentido, torna-se uma ameaça à identidade étnico-lingüística local". Como as pessoas participam de diferentes círculos em suas vidas: família, religião, escola, possuem, em cada um desses círculos, diferentes letramentos e essas participações constituem as identidades da linguagem.

Ao tomarmos como definição de letramento a explicação de Soares (2001, p.1718): "estado ou condição que assume aquele que aprende a ler e escrever" e a explicação de que "nesse conceito está a idéia de que a escrita traz conseqüências sociais, culturais, políticas, econômicas, cognitivas, linguísticas, quer para o grupo social em que está introduzida, quer para o indivíduo que aprenda a usá-la", depreendemos que letramento é o resultado da ação de ensinar ou de aprender a ler e escrever, mas também de fazer uso da leitura e da escrita em práticas sociais.

Para que haja condições para o letramento é necessário acontecer a escolarização efetiva. O letramento possui duas faces: a individual (vista como atributo pessoal das faculdades de ler e de escrever) e a social (vista como fenômeno cultural, conjunto de atividades sociais que exigem o domínio da língua escrita e a capacidade de compreender diferentes textos).

Estudiosos que entendem que o letramento refere-se a "o que as pessoas fazem com as habilidades da leitura e da escrita em um contexto específico e como essas habilidades se relacionam com as necessidades, valores e práticas sociais" (SOARES, 2001, p.72) formam a corrente do letramento "funcional" - o indivíduo precisa estar apto a "funcionar" em um contexto social e isso só será possível se as suas habilidades 
de escrita e leitura estiverem suprindo as suas necessidades de usos naquele contexto (aqui entendido como grupo social, comunidade). O letramento funcional propicia a sobrevivência do indivíduo na comunidade, pois, em todos os momentos, habilidades de leitura (placas nas ruas, placas nos ônibus, ofertas em mercados, etc.) e de escrita (anotar recados, escrever bilhetes, etc.) são exigidas das pessoas.

Há também, segundo Soares (2001, p.74-75), estudiosos que caracterizam o letramento como conjunto de práticas sociais que envolvem a leitura e a escrita, "responsáveis por reforçar, questionar ou modificar valores, tradições e formas de distribuição de poder nos contextos sociais". Street (1984) nos orienta que letramento é o conjunto de práticas sociais e concepções de leitura e escrita que não podem ser dissociados de determinado contexto. O autor denomina o letramento de "ideológico", pois as práticas sociais que envolvem a escrita $\mathrm{e}$ a leitura resultam em modificações/conservações sociais; nesse caso, o letramento é visto como um instrumento transmissor de ideologia.

Cabe à escola, nos moldes da sociedade atual, promover o letramento (embora esse não seja o único meio de se adquirir/desenvolver letramento); nesse contexto (escolar), o letramento é (ou deveria ser) um processo contínuo que provê crianças, jovens e adultos das habilidades, conhecimentos, crenças e valores essenciais e capazes de torná-los indivíduos integrados e participantes da sociedade - cidadãos. Para alcançar tal objetivo, a escola "elege" alguns conhecimentos, algumas práticas de leitura e escrita, organiza-as no "tempo escolar" (espaço de tempo que os indivíduos se fazem presentes na escola) e os avalia para a continuidade do processo, através de formas tradicionais (avaliações, trabalhos escolares) ou não (atividades diferenciadas pensadas em função de determinado conteúdo de conhecimento). É verdadeira a observação feita por Moita Lopes e Rojo (2004, p.46), enfatizada em Rojo (2009, p.89):

São muitos os discursos que nos chegam e são muitas as necessidades de lidar com eles no mundo do trabalho e fora do trabalho, não só para o desempenho profissional, como também para fazer escolhas éticas [...]. Ensinar a usar e a entender como a linguagem funciona no mundo é tarefa crucial da escola na construção da cidadania [...]

e, as práticas de uso da escrita, segundo Signorini (2008, p.125), estão sempre

Atreladas à história individual do escrevente/leitor (papéis assumidos, posição social, objetivos, etc.) e da(s) comunidade(s) de que participa (estruturas da ordem social e política, divisão do trabalho, tradições culturais, etc.), bem como aos diferentes campos de atividades do cotidiano e suas respectivas instituições de referência: atividades relacionadas ao lar (família), à escola e ao trabalho (Barton, 1991); e também à religião.

Ao falar do letramento escolar, lembramos de Ferreiro e Teberosky (1985, p.11) que nos alertam que o processo é iniciado "muito antes do que a escola imagina" $\mathrm{e}$ Street (2006, p.472) que diz que "o fato de uma forma cultural ser dominante é disfarçado por trás de discursos públicos de neutralidade e tecnologia nos quais o letramento dominante é apresentado como o único letramento". O letramento padrão (escolar) é apenas uma das variedades e a escolha por uma delas (variantes) é igualmente uma questão de poder. Jung (2007, p.85), embasada nos ensinamentos de Street, nos traz que as práticas de letramentos "seriam social e culturalmente determinadas, o que equivale a dizer que os significados específicos que a escrita assume para um grupo social dependem dos contextos e das instituições em que ela é adquirida e praticada". 
Na escola, de acordo com Street (2014), ainda hoje, prevalece a tendência tecnicista que está fundamentada na ideia de que o letramento é um saber abstrato que se sustenta em operações mentais e, nesse caso, saber ler e escrever não dependeria de outros conhecimentos e o seu ensino (da leitura e da escrita) atenderia às necessidades do mercado de trabalho. Para formar cidadãos críticos e participantes da sociedade, deveria haver, por parte da escola, letramentos com a finalidade de promover a aprendizagem de conhecimentos que levassem ao desenvolvimento integral, intelectual e social dos alunos que almejem a verdadeira cidadania; a educação não pode se valer somente da reprodução de conhecimentos, pois ela é o lugar da transformação.

Embora haja uma tendência, tanto por parte da escola, como por parte das políticas educacionais, em escolher a língua inglesa (a língua espanhola também vem conquistando o seu espaço) para compor a grade curricular; no Estado do Paraná, em meados da década de 80, com a redemocratização do país, os professores de línguas estrangeiras, organizados em associações, lideraram um amplo movimento pelo retorno da pluralidade da oferta de línguas estrangeiras nas escolas públicas, através dos CELEMs. Dessa forma, os CELEMs oferecem várias línguas dentro de suas possibilidades e as comunidades escolhem as línguas que mais lhes convêm, conforme prescrito nas DCEs.

O referencial teórico que sustenta o documento das DCEs é a pedagogia crítica "que valoriza a escola como espaço social democrático, responsável pela apropriação crítica e histórica do conhecimento como instrumento de compreensão das relações sociais e para a transformação da realidade" (PARANÁ, 2008, p.52). Assim, a proposta para as aulas de LEM, dentro das DCEs, baseia-se na corrente sociológica e nas teorias do Círculo de Bakhtin, que concebem a língua como discurso, propiciando

Um espaço para que o aluno reconheça e compreenda a diversidade lingüística e cultural, de modo que se envolva discursivamente e perceba possibilidades de construção de significados em relação ao mundo em que vive. Espera-se que o aluno compreenda que os significados são sociais e historicamente construídos e, portanto, passíveis de transformação na prática social (PARANÁ, 2008, p.53)

Para Bakhtin (1988), não há discurso individual, pois a construção (do discurso) se dá no processo de interação e em função do outro. Sob essa visão, o ensino de língua estrangeira deve pautar-se no contexto da interação verbal e não no sistema linguístico. Segundo as DCEs (2008, p.55):

No ensino de Língua Estrangeira, a língua, objeto de estudo dessa disciplina, contempla as relações com a cultura, o sujeito e a identidade. [...] ensinar e aprender língua é também ensinar e aprender percepções de mundo e maneiras de atribuir sentidos, é formar subjetividades, é permitir que se reconheça no uso da língua os diferentes propósitos comunicativos, independente do grau de proficiência atingido.

Portanto, o ensino de língua estrangeira tem como objetivo contribuir para a formação de cidadãos capazes de participar criticamente no mundo e capazes de transitar em sociedades onde há identidades culturais múltiplas. O CELEM é uma das formas de descendentes de imigrantes aprenderem/praticarem a língua de seus pais/avós e conhecerem um pouco mais da cultura de seus antepassados. Ao observarmos as práticas de letramentos presentes no CELEM da localidade de Santana, no município de Cruz Machado, vimos que eram trabalhados aspectos culturais da Polônia, como esses traços identitários chegaram ao Brasil e como são vivenciados atualmente. Consideramos esse procedimento de grande valia para as pessoas que frequentavam o 
CELEM, pois ele corrobora as ideias de Bhabha (2003) de que o ser humano encontrase em constantes atos de se reconstruir e de se reinventar.

\section{Conclusão}

Procuramos traçar, neste artigo, algumas considerações iniciais (tendo em vista a pesquisa estar também em fase inicial e haver muito a ser estudado) sobre a constituição de identidades étnico-linguísticas presentes nos municípios de São Mateus do Sul e de Cruz Machado, ambos no interior do Estado do Paraná e constituídos em grande parte por descendentes de imigrantes poloneses. Junto às verificações "in loco" sobre traços identitários presentes em práticas religiosas e práticas de letramentos, trouxemos algumas ideias e ensinamentos de pesquisadores e estudiosos nos assuntos (identidades e letramentos). Para corroborar o abordado no artigo, transcrevemos a seguir dois trechos de duas entrevistas realizadas com descendentes de poloneses em São Mateus do Sul (as identidades dos informantes serão mantidas em sigilo).

(01) "Meus avós e meus pais sempre falavam o polonês em casa. A minha primeira língua foi o polonês [...] comecei a aprender o português quando ia brincar com os vizinhos e depois ao ingressar na escola”. (E.J.D.)

(02) "Quando fomos à escola, nas séries iniciais, sofremos um pouco porque a professora exigia que tudo fosse falado em português e às vezes misturávamos as línguas... um pouco português, um pouco polonês ... [...] temos muita influência nos costumes e tradições, principalmente na religiosidade, visto que são católicos fervorosos... as orações antes das refeições também são feitas em polonês, principalmente nos encontros da família [...] também no sábado de aleluia era realizada a bênção dos alimentos ...sempre participávamos ajudando minha avó a levar os alimentos em cesta de vime para o padre benzer". (L.R.G.).

\section{REFERÊNCIAS}

BAGNO, M.; RANGEL, E. de O. Tarefas da educação lingüística no Brasil. Revista Brasileira de Lingüística Aplicada, v.5, n.1, p. 63-81, 2005.

BAKHTIN, M. Marxismo e filosofia da linguagem. São Paulo: Hucitec, 1988. 196 p.

BHABHA, H. K. O local da cultura. Tradução de Myriam Ávila, Eliana L. de L. Reis e Glaucia K. Gonçalves. Belo Horizonte: Ed. UFMG, 2003. 395 p.

CORACINI, M. J. R. F. Identidade e Discurso. Campinas: Editora da UNICAMP, 2003. $385 \mathrm{p}$.

DUBOIS, J. et al. Dicionário de Lingüística. São Paulo: Cultrix, 2007. 653 p.

FERREIRO, E.; TEBEROSKY, A. Psicogênese da língua escrita. Porto Alegre: Artmed, 1985. 284 p.

HALL, S. Quem precisa de identidade? In: SILVA, T. T. da (org.). Identidade $e$ Diferença: A perspectiva dos estudos culturais. 9. ed. Petrópolis: Vozes, 2009. 133 p.

HOBSBAWM, E. Nações e nacionalismo desde 1780: programa, mito e realidade. 3. ed. Rio de Janeiro: Paz e Terra, 1990. 117 p.

JUNG, N. M. A relação entre identidade de gênero, identidade étnico-linguiística e as práticas de letramento em uma comunidade multilíngüe no Brasil. II Simpósio Internacional de Bilinguismo. Universidade de Vigo. Disponível em: <www.webs.uvigo.es/ssl/actas 2002/05/05>, p.1187-1206, 2002. 
Letramento: uma concepção de leitura e escrita como prática social. In: CORREA, D. A.; SALEH, P. B. de Oliveira (Orgs.). Práticas de letramento no ensino: leitura, escrita e discurso. São Paulo: Parábola/Ed. UEPG, 2007. 150 p.

OLIVEIRA, M. de. Organizações sociais dos imigrantes poloneses e seus descendentes em Curitiba (Brasil, 1890-1938). In: MARTINS, I. L.; HECKER, A. (Orgs.). E/imigrações: histórias, culturas, trajetórias. São Paulo: Expressão e Arte Editora, 2010. $326 \mathrm{p}$.

PARANÁ. Secretaria de Estado da Educação. Superintendência de Educação. Departamento de Educação Básica. Diretrizes Curriculares da Educação Básica: Língua Estrangeira Moderna. Curitiba: SEED, 2008. 88 p.

RODRIGUES, A. D. Problemas relativos à descrição do português contemporâneo como língua padrão no Brasil. In: BAGNO, M. (Org.). Lingüística da norma. São Paulo: Loyola, 2002. p.11-25.

ROJO, R. Letramentos múltiplos, escola e inclusão social. São Paulo: Parábola, 2009. $127 \mathrm{p}$.

SIGNORINI, I. Construindo com a escrita "outras cenas de fala". In: MARCUSCHI, L. A.; SIGNORINI, I. (Orgs.). Investigando a relação oral/escrito e as teorias do letramento.Campinas: Mercado de Letras, 2008. 192 p.

SOARES, M. Letramento: um tema em três gêneros. Belo Horizonte: Autêntica, 2001. $125 \mathrm{p}$.

Alfabetização e letramento. São Paulo: Contexto, 2002. 125 p.

STREET, B. Literacy in theory and practice. Cambridge: Cambridge University Press, 1984. $243 \mathrm{p}$.

Perspectivas interculturais sobre o letramento. Tradução de Marcos Bagno. Revista de Filologia e Lingüística Portuguesa, n.8, p.465-488, 2006.

Letramentos sociais: Abordagens críticas do letramento no desenvolvimento, na etnografia e na educação. Tradução de Marcos Bagno. São Paulo: Parábola, 2014. $238 \mathrm{p}$.

WACHOWICZ, R. C. A "febre brasileira" na imigração polonesa. In: Anais da Comunidade Brasileiro-Polonesa. v. I - Ano 1970. Curitiba: Superintendência das Comemorações do Centenário da Imigração Polonesa ao Paraná, 1970a. 128 p.

As escolas da colonização polonesa no Brasil. In: Anais da Comunidade Brasileiro-Polonesa. v. II - Ano 1970. Curitiba: Superintendência das Comemorações do Centenário da Imigração Polonesa ao Paraná, 1970b. 128 p.

Martins, 1981. $149 \mathrm{p}$.

O camponês polonês no Brasil. Curitiba: Fundação Cultural Casa Romário

WOODWARD, K. Identidade e diferença: uma introdução teórica e conceitual. In: SILVA, T. T. da (org.). Identidade e Diferença: A perspectiva dos estudos culturais. 9. ed. Petrópolis: Vozes, 2009. 133 p.

Recebido em: 29/09/2015

Aprovado em: 07/07/2016 